\title{
The Emergency Department Arrival Mode and Its Relations to ED Management and 30-Day Mortality in Acute Heart Failure: An Ancillary Analysis From The EURODEM Study
}

Pia Harjola ( $\nabla$ pia.harjola@helsinki.fi )

Hospital District of Helsinki and Uusimaa: Helsingin ja Uudenmaan sairaanhoitopiiri

https://orcid.org/0000-0003-2425-3080

Tuukka TARVASMÄKI

University of Helsinki and Heart and Lung Center

Cinzia BARLETTA

Urgencias Hospital Marqués de Valdecilla

Richard BODY

The University of Manchester

Jean CAPSEC

Department of Public Health

Michael CHRIST

Department of Emergency Care

Luis GARCIA-CASTRILLO

Servicio Urgencias Hospital Marqués de Valdecilla

Adela GOLEA

University of Medicine and Pharmacy

Mehmet KARAMERCAN

Gazi University

Paul-Louis MARTIN

Medicine Department

Oscar MIRO

University of Barcelona

Jukka TOLONEN

Helsinki University Hospital

Ari PALOMÄKI

Kanta-Häme Central Hospital

Franck VERSCHUREN

Department of Acute Medicine

Veli-Pekka HARJOLA 
Helsinki University Hospital

\section{Said LARIBI}

Tours University

\section{Original research}

Keywords: acute heart failure, arrival mode, management, prognosis, emergency medical services, ventilatory support

Posted Date: January 16th, 2021

DOl: https://doi.org/10.21203/rs.3.rs-139434/v1

License: (c) (1) This work is licensed under a Creative Commons Attribution 4.0 International License. Read Full License

Version of Record: A version of this preprint was published at BMC Emergency Medicine on February 14th, 2022. See the published version at https://doi.org/10.1186/s12873-022-00574-z. 


\section{Abstract}

Background: Acute heart failure patients are often encountered in emergency departments from $11 \%$ to $57 \%$ using emergency medical services. Our aim was to evaluate the association of emergency department arrival mode with acute heart failure patients' emergency department management and shortterm outcomes.

Methods: This was a sub-analysis of the European EURODEM study. Data on patients presenting with dyspnoea were collected prospectively from 66 European emergency departments. Patients with emergency department diagnosis of acute heart failure were categorized into two groups: those using emergency medical services and those self-presenting (non- emergency medical service patients). The independent association between emergency medical services use and 30-day mortality was evaluated with logistic regression.

Results: Of the 500 acute heart failure patients, 309 (61.8\%) arrived at emergency department by emergency medical services. They were older (median age 80 vs. 75 years, $p<0.001$ ) and had more dementia $(18.7 \%$ vs. $7.2 \%$, $\mathrm{p}<0.001)$. On admission, emergency medical service patients had more often confusion (43 $(14.2 \%)$ vs. $4(2.1 \%), p<0.001)$ and higher respiratory rate $(24 / \mathrm{min}$ vs. $21 / \mathrm{min}, \mathrm{p}=0.014$; respiratory rate $>30 / \mathrm{min}$ in $17.1 \%$ patients vs. $7.5 \%, p=0.005)$. The only difference in emergency department management appeared in the use of ventilatory support: $78.3 \%$ of emergency medical services patients vs. $67.5 \%$ of non- emergency medical services patients received oxygen, $p=0.007$, noninvasive ventilation was administered to $12.5 \%$ of emergency medical service patients vs. $4.2 \%$ nonemergency medical service patients, $p=0.002$. Emergency medical service patients were more often hospitalized ( $82.4 \%$ vs. $65.9 \%, p<0.001)$. The use of emergency medical services was an independent predictor of 30-day mortality $(\mathrm{OR}=2.96,95 \% \mathrm{Cl} 1.27-6.92, \mathrm{p}=0.012)$

Conclusion: Most acute heart failure patients arrive at emergency department by emergency medical services. These patients suffer from more severe respiratory distress and receive more often ventilatory support. Emergency medical service use is an independent predictor of 30-day mortality.

\section{Background}

Acute heart failure (AHF) is a life-threatening condition encountered in emergency departments (ED) worldwide. The proportion of AHF patients arriving at the ED by EMS (emergency medical services) varies from $11 \%$ to $57^{1-7}$.

The main complaint of AHF is shortness of breath ${ }^{3,8}$. One of the main goals of AHF management (in addition to stabilisation of hemodynamic) is to relieve patients' symptoms and to reduce fluid overload. Intravenous (IV) diuretics and vasodilators are the mainstay of AHF management ${ }^{9}$. Registries show that approximately $80 \%$ of AHF patients are treated with IV diuretics ${ }^{1,10-15}$. However, less than half of AHF 
patients receive IV vasodilators ${ }^{1,10-14,16}$. Non-invasive ventilation (NIV) is administered to $7-20 \%$ of AHF patients $1,2,11,13,14,16,17$.

Earlier studies regarding AHF patients' EMS use have focused on clinical factors associated with the use and the prognostic effects of EMS ${ }^{4,5}$. The aim of this study was to determine whether the arrival mode is associated with the administration of AHF treatments in ED, in addition to the patient outcomes.

\section{Methods}

This study was a sub-analysis of the prospective, multinational EURODEM study ${ }^{18}$. Data was received from 66 European EDs: Belgium ( $n=3)$, Finland $(n=5)$, France $(n=5)$, Germany $(n=5)$, Italy $(n=1)$, the Netherlands $(n=16)$, Romania $(n=7)$, Spain $(n=1)$, Turkey $(n=7)$ and United Kingdom $(n=16)$.

The EURODEM study included patients presenting to ED with shortness of breath, dyspnoea being one of the symptoms listed in the triage on ED admission. The data was collected in three 72-hour periods (February, May and October 2014) by local ED nurses or physicians. ED diagnoses were recorded. The physician made the ED diagnosis based on, patient history, clinical assessment, imaging, and laboratory tests. Patients with ED diagnosis of AHF were included to this analysis. The AHF patients were categorized based on their ED arrival mode: those arriving by EMS (EMS patients) and those selfpresenting (non-EMS patients). The collected data included patient characteristics, initial assessment (clinical assessment and vital signs), laboratory tests, ED management, in-hospital outcomes, and 30-day mortality. The 30-day outcome was ascertained by a follow-up phone call. The study was performed in accordance with the Declaration of Helsinki. The approval of local ethics committee was received from all participating centres according to local requirements. In most participating centres patient consent for data collection was received.

For analyses, a systolic blood pressure (SBP) $<100 \mathrm{mmHg}$ was considered as 'hypotension' and SBP $>140 \mathrm{mmHg}$ as 'hypertension'. Respiratory distress was defined as respiratory rate (RR) $>30$ breaths $/ \mathrm{min}$. The peripheral oxygen saturation $\left(\mathrm{SpO}_{2}\right)$ was measured after 30-minute oxygenation. Categorical variables are reported as numbers and percentages (\%) and continuous variables as medians with interquartile range (IQR). Between-group comparisons were performed with chi-square test for categorical variables and Mann-Whitney $U$ test for continuous variables. For assessment of independent predictors of 30-day mortality, we used forward and backward selection of variables in logistic regression to calculate likelihood ratios, with significance $<0.05$ for inclusion and $>0.1$ for elimination. The variables in the selection process were based on clinical relevance and previous literature $19,20,21,22$. To retain adequate sample size, variables with more than $10 \%$ of missing data were excluded. Consequently, the following variables were tested in the selection models: age, gender, ED arrival mode, SBP, heart rate (HR), $\mathrm{SpO}_{2}$, sodium, potassium, confusion, a history of chronic obstructive pulmonary disease (COPD) and active cancer. Variables were retained in the final multivariable model if $p$-value was less than 0.05 . IBM SPSS version 25 was used for statistical analysis. A p-value below 0.05 was considered statistically significant. 


\section{Results}

The EURODEM study included 2525 patients of which 507 had AHF as ED diagnosis. Data from the arrival mode was missing from seven patients, which were excluded from the analyses. The majority of AHF patients ( $n=309(61.8 \%)$ ) arrived at the ED by EMS. Compared to non-EMS patients, EMS patients were older (median age $80(71-85)$ years vs. $75(65-81)$ years, $p<0.001)$ and more often female (173 (56.4 $\%)$ vs. $80(42.1 \%), p=0.002)$ (Table 1 ).

A total of $290(60.9 \%)$ patient had a previous diagnosis of HF. No significant differences existed between the groups. EMS patients had more often dementia and a history of pulmonary embolism, whereas diabetes was more common in non-EMS patients. No other major differences in the prevalence of comorbidities were observed between the groups (Table 1). The median duration of dyspnoea before ED admission was 3 days in both groups (EMS 3 (1-7) days vs non-EMS 3 (2-10) days, $p=0.002$ ) (Table 1 ).

On admission to ED, the median SBP of all AHF patients was 140 (120-159) mmHg. Only 27 (5.5\%) patients had SBP below $100 \mathrm{mmHg}$, whereas 243 (49.3\%) patients had SBP over $140 \mathrm{mmHg}$. The median HR of all AHF patients was 88 (75-110) beats per minute (bpm). No significant differences appeared in BP or HR levels between the groups. On admission, EMS patients were more tachypnoeic (RR 24 (19-30) breaths/min vs. 21 (18-26) breaths/min, p=0.014). Forty-three (17.1\%) EMS patients had a RR higher than 30 breaths/min compared to $12(7.5 \%)$ non-EMS patients, $\mathrm{p}=0.005$. The median $\mathrm{SpO}_{2}$ after 30 min oxygenation was $94 \%$ in both groups. Of all AHF patients, $346(71.8 \%)$ were reported to have rales on lung auscultation; EMS patients more often (228 (76.8\%) vs. $118(63.8 \%), p=0.002)$. Wheezing was also more common in the EMS group (62 (23.1\%) vs. 25 (14.4\%), p=0.024) (Table 2).

Regarding laboratory tests, NT-proBNP was measured in 122 (24.4 \%) AHF patients and BNP in 52 (10.4 \%) patients. NT-proBNP was measured significantly more often in EMS patients (Figure 1) and the levels were significantly higher (median 5144 (1846-11205) pg/mL vs 2103 (688-5167) pg/mL, $p=0.001$ ). The median pH of all AHF patients was 7.40 (7.34-7.45) (Table 2). EMS patients had significantly lower blood $\mathrm{pH}$ values (7.38 (7.32-7.44) vs 7.43 (7.37-7.46), $\mathrm{p}=0.002)$ (Table 2).

Figure 2 shows the frequency of AHF management in the ED. Intravenous diuretics were administered to $335(68 \%)$ AHF patients, whereas nitrate infusion was administered to $60(13 \%)$. The only significant difference in the use of ED management between the two groups appeared in ventilatory support, which was significantly more often provided to EMS patients: supplementary oxygen to 242 (78.3\%) EMS patients vs. $129(67.5 \%)$ non-EMS patients ( $p=0.007)$, and NIV to $38(12.5 \%)$ EMS patients vs. $8(4.2 \%)$ non-EMS patients $(\mathrm{p}=0.002)$. In univariate analysis lower $\mathrm{SpO}_{2}(\mathrm{p}<0.001)$ and higher respiratory rate $(p<0.001)$ were associated to NIV use. Fourteen $(2.8 \%)$ patients received mechanical ventilation; no difference appeared between the patient groups (11 (3.6 \%) EMS patients vs. 3 (1.6\%) non-EMS, $\mathrm{p}=0.191)$. Patients reported to have confusion were intubated significantly more often compared to the rest of the AHF patients (10 (21.7\%) patients vs. 4 (0.9\%) patients, $p<0.001)$. 
Seventy-six percent $(n=365)$ of all AHF patients were hospitalized from the ED, EMS patients more frequently compared to non-EMS (238 (82.4\%) vs. 120 (65.9), $p<0.001$. The majority of all AHF patients (291 (58.2\%)) were admitted to a ward, EMS patients more often (192 (62.1\%) EMS patients vs. 99 (51.8 $\%$ ) non-EMS patients, $\mathrm{p}=0.013$ ) (Figure 3).

The median length of hospital stays (LOS) was 7 (2-12) days in both groups (EMS 7 (3-13) days vs. nonEMS 7 (1-11) days, $p=0.058$ ). The all-cause in-hospital mortality was $6.6 \%$ (33 patients); Twenty-seven (8.7\%) EMS patients and six (3.1\%) non-EMS patients died during hospitalization ( $\mathrm{p}=0.014)$. The 30 -day mortality was significantly higher in the EMS group (40 (14.3\%) EMS patients vs. 9 (4.9\%) non-EMS patients, $p<0.001$ ) (Figure 3). In addition, multivariable logistic regression showed that the arrival by EMS was an independent predictor of 30-day mortality $(\mathrm{OR}=2.96,95 \% \mathrm{Cl} 1.27-6.92, \mathrm{p}=0.012)$. The other independent predictors were female gender (OR 0.46, 95\% Cl 0.23-0.93 $p=0.031$ ), active cancer (OR 3.44, $95 \% \mathrm{Cl} 1.14-10.41, p=0.029$ ), confusion (OR 6.45, 95\% Cl $2.76-15.08, p<0.001$ ), and sodium level (OR $0.90,95 \% \mathrm{Cl} 0.85-0.96, \mathrm{p}=0.001)$.

\section{Discussion}

This study describes the association of ED arrival mode with AHF management in the ED and patient outcomes. Firstly, this study shows that in Europe the majority of AHF patients arrived at the ED by EMS. These patients were more likely to be older females with dementia than the patients self-presenting. Secondly, patients arriving at the ED by EMS suffered more often from respiratory distress, and consequently received more often ventilatory support. However, no other differences were observed in the administration frequencies of AHF treatments in the ED. Thirdly, EMS patients had worse short-term outcomes and the use of EMS was an independent predictor of 30-day mortality.

In the present study, the proportion of AHF patients using EMS is among the highest in the literature ${ }^{1-7,23}$. In line with the previous studies, older women were more prone to use EMS ${ }^{3-5}$. However, the comorbidities associated with the EMS use differed between these studies. In our study, EMS patients tended to have more dementia and a history of pulmonary embolism compared to non-EMS patients. In a Finnish study, EMS patients had more often cardiovascular disease and chronic kidney disease (CKD) ${ }^{3}$, in Spain cardiovascular diseases, CKD, COPD, and dementia were more prevalent ${ }^{4}$, and in North America the only more prevalent comorbidity was hypertension ${ }^{5}$. Most AHF patients had a history of HF. Contrary to some of the earlier studies no significant difference occurred between EMS and non-EMS patients ${ }^{3,5}$.

Although most initial parameters, such as $\mathrm{SpO}_{2}, \mathrm{HR}$ or $\mathrm{BP}$, did not differ between the patient groups, EMS patients suffered more often from respiratory distress, had abnormal breath sounds, confusion, higher levels of NT-proBNP, and lower $\mathrm{pH}$, reflecting more severe clinical presentation of AHF, especially pulmonary oedema ${ }^{24}$. As also reported earlier ${ }^{5}$, the EMS patients had shorter duration of symptoms before ED admission, which may also reflect the more severe clinical presentation. 
Respiratory distress is one of the most common reasons for EMS use ${ }^{25}$, as also seen in our study. Due to more severe respiratory distress, EMS patients received more often ventilatory support compared to their counterparts. Although, the use of NIV in the EMS group was about the average compared to earlier studies $1,2,11,13,14,16,17$, it was fairly low in light of the ESC guidelines ${ }^{9}$. Naturally, the use of NIV and supplementary oxygen were associated to higher RR and lower Sp02. However, one fourth of all the AHF patients in our study had $\mathrm{SpO}_{2}$ less than $90 \%$ with supplementary oxygen, suggesting that NIV might have been indicated more often in both patient groups. Yet, $14 \%$ of EMS patients were reported to have confusion, one of the contraindications for NIV use, which could partly explain the relatively low frequency of NIV use. Moreover, one fifth of all the patients reported to have confusion were intubated, which was significantly more often compared to the rest of the AHF patients.

Since the clear majority of AHF patients present with congestion without hypoperfusion and hypotension $9,10,26$, vasodilators and diuretics are the mainstay of AHF management ${ }^{9}$. Although only $5 \%$ of all AHF patients in our study were hypotensive and half hypertensive, only one patient out of eight received nitrate infusion. The underuse of vasodilators has been observed previously as well ${ }^{10,11,15}$. In contrast, diuretics were given to $70 \%$ of patients. All in all, there is room for improvement in the ED management of AHF as also pointed out earlier ${ }^{4}$.

Finally, EMS patients were more often admitted to a ward and, in line with previous studies, had significantly higher in-hospital 4,7 and 30-day mortality 4, 5,727. Indeed, EMS patients seemed more fragile and severely ill ${ }^{3,4}$ and the same factors related to EMS use - female gender and confusion- were also observed among the independent predictors of 30-day mortality. Notably, confusion was a strong marker for increased risk of death as well, which warrants our attention to asses mental state not only in the most severe AHF, i.e. cardiogenic shock ${ }^{28}$, but in all AHF patients. Still, as also shown earlier ${ }^{5,7,27}$ EMS use remained an independent predictor of 30-day mortality, which may be linked to patients' fragility and illness severity affected by unmeasured and unknown confounders, as well to patient preference. All in all, the selection of AHF patients for EMS transportation by dispatch centres and EMS seems reasonable in Europe.

\section{Limitations}

Some limitations need to be addressed. First, we didn't have information about the criteria for EMS referral in different EMS regions. Second, our data did not include chest x-ray findings even though the clinician used imagining in decision making. Yet, the chest $x$-ray is known to have limited specificity and sensitivity ${ }^{9,17}$. Third, the doses of AHF medications were not registered. Those might have differed between EMS and non-EMS patients due to difference in disease severity, but the overall use of AHF medications was similar. Fourth, there was a fair amount of missing data in some of the variables, especially in biochemistry, warranting caution in the interpretation of the results from the multivariable analyses. 


\section{Conclusion}

In conclusion, our study shows that the majority of AHF patients arrive at the ED by EMS. Older age, female gender, dementia, confusion, and especially respiratory distress seem to be the driving forces for EMS use. Apart from the more frequent use of respiratory support, the use of AHF treatments in the ED does not differ between EMS and non-EMS patients. EMS patients are more often admitted to a ward and the use of EMS is an independent predictor of 30-day mortality. More prospective research should be done in the pre-hospital phase to discover the reasons for differences in the outcomes between EMS and non-EMS patients.

\section{Abbreviations}

$\mathrm{AHF}=$ acute heart failure

$E D=$ emergency department

EMS $=$ emergency medical services

IV = intravenous

NIV = non-invasive ventilation

SBP = systolic blood pressure

$\mathrm{RR}=$ respiratory rate

$\mathrm{SpO}_{2}=$ peripherial oxygen saturation

$\mathrm{IQR}=$ inter quartile range

$\mathrm{HR}=$ heart rate

COPD $=$ chronic obstructive pulmonary disease

LOS = length of hospital stay

$\mathrm{CKD}=$ chronic kidney disease

\section{Declarations}

Ethics approval and consent to participate: The study was performed in accordance with the Declaration of Helsinki. Patient consent for data collection was received according to local policies.

Consent for publication: Not applicable 
Availability of data and materials: The EURODEM database is not publicly available.

Competing interests: None to declare

Funding: $\mathrm{PH}$ has received funding from Department of Emergency Medicine and Services, Helsinki University Hospital.

For the remaining authors none were declared.

Authors contribution: $\mathrm{PH}$ : analysis and interpretation of data, main author of the manuscript. TT: analysis and interpretation of data, critical revision of manuscript. CB: critical revision. RB: critical revision. JC: critical revision. MC: critical revision. LGC: critical revision. AG: critical revision. MK: critical revision. PLM: critical revision. ÒM: critical revision. JT: critical revision. OVM: critical revision. AP: critical revision. FV: critical revision. VPH: critical revision. SL: critical revision.

Acknowledgements: Data management in Europe was facilitated by the Jeroen Bosch Hospital. The EURODEM Steering Committee: Said Laribi (Chair, France), Oene van Meer (the Netherlands), Richard Body (United Kingdom), Mehmet Karamercan (Turkey), Veli-Pekka Harjola (Finland), Adela Golea (Romania), Franck Verschuren (Belgium), Michael Christ (Germany), Cinzia Barletta (Italy) and Luis Garcia-Castrillo (Spain)

EURODEM Study Group members are listed in the Supplemental Digital Content.

\section{References}

1. Chouihed T, Manzo-Silberman S, Peschanski N, et al. Management of suspected acute heart failure dyspnea in the emergency department: results from the French prospective multicenter DeFSSICA survey. Scand J Trauma Resusc Emerg Med 2016; 24: 112. DOI: 10.1186/s13049-016-0300-x [doi].

2. Logeart $D$, Isnard $R$, Resche-Rigon $M$, et al. Current aspects of the spectrum of acute heart failure syndromes in a real-life setting: the OFICA study. Eur J Heart Fail 2013; 15: 465. DOI: 10.1093/eurjhf/hfs189 [doi].

3. Harjola P, Boyd J, Tarvasmaki T, et al. The impact of emergency medical services in acute heart failure. Int J Cardiol 2017; 232: 222. DOI: S0167-5273(17)30036-0 [pii].

4. Miro $\mathrm{O}$, Llorens $\mathrm{P}$, Escalada $\mathrm{X}$, et al. Prehospital emergency care of patients with acute heart failure in Spain: the SEMICA study (Emergency Medical Response Systems for Patients with Acute Heart Failure). Emergencias 2017; 29: 223.

5. Ezekowitz JA, Podder M, Hernandez AF, et al. Arrival by ambulance in acute heart failure: insights into the mode of presentation from Acute Studies of Nesiritide in Decompensated Heart Failure (ASCEND-HF). BMJ Open 2016; 6: e010201. DOI: 10.1136/bmjopen-2015-010201 [doi].

6. Llorens P, Javaloyes P, Martin-Sanchez FJ, et al. Time trends in characteristics, clinical course, and outcomes of 13,791 patients with acute heart failure. Clin Res Cardiol 2018; 107: 897-913. 
2018/05/08. DOI: 10.1007/s00392-018-1261-z.

7. Wong YW, Fonarow GC, Mi X, et al. Early intravenous heart failure therapy and outcomes among older patients hospitalized for acute decompensated heart failure: findings from the Acute Decompensated Heart Failure Registry Emergency Module (ADHERE-EM). Am Heart J 2013; 166 : 349-356. 2013/07/31. DOI: 10.1016/j.ahj.2013.05.014.

8. Adams KF, Jr., Fonarow GC, Emerman CL, et al. Characteristics and outcomes of patients hospitalized for heart failure in the United States: rationale, design, and preliminary observations from the first 100,000 cases in the Acute Decompensated Heart Failure National Registry (ADHERE). Am Heart J 2005; 149: 209. DOI: S0002870304004995 [pii].

9. Ponikowski P, Voors AA, Anker SD, et al. 2016 ESC Guidelines for the diagnosis and treatment of acute and chronic heart failure: The Task Force for the diagnosis and treatment of acute and chronic heart failure of the European Society of Cardiology (ESC)Developed with the special contribution of the Heart Failure Association (HFA) of the ESC. Eur Heart J 2016; 37: 2129-2200. May 20. DOI: 10.1093/eurheartj/ehw128. .

10. Chioncel O, Mebazaa A, Harjola VP, et al. Clinical phenotypes and outcome of patients hospitalized for acute heart failure: the ESC Heart Failure Long-Term Registry. Eur J Heart Fail 2017; 19: 1242. DOI: 10.1002/ejhf.890 [doi].

11. Tarvasmaki T, Harjola VP, Tolonen J, et al. Management of acute heart failure and the effect of systolic blood pressure on the use of intravenous therapies. Eur Heart J Acute Cardiovasc Care 2013; 2: 219-225. 2013/11/14. DOI: 10.1177/2048872613492440.

12. Maggioni AP, Anker SD, Dahlstrom U, et al. Are hospitalized or ambulatory patients with heart failure treated in accordance with European Society of Cardiology guidelines? Evidence from 12,440 patients of the ESC Heart Failure Long-Term Registry. Eur J Heart Fail 2013; 15: 1173-1184. 2013/08/28. DOI: 10.1093/eurjhf/hft134.

13. Nieminen MS, Brutsaert D, Dickstein K, et al. EuroHeart Failure Survey II (EHFS II): a survey on hospitalized acute heart failure patients: description of population. Eur Heart J 2006; 27: 2725-2736. 2006/09/27. DOI: 10.1093/eurheartj/ehl193.

14. Follath F, Yilmaz MB, Delgado JF, et al. Clinical presentation, management and outcomes in the Acute Heart Failure Global Survey of Standard Treatment (ALARM-HF). Intensive Care Med 2011; 37 : 619-626. 2011/01/07. DOI: 10.1007/s00134-010-2113-0.

15. Maggioni AP, Dahlstrom U, Filippatos G, et al. EURObservational Research Programme: the Heart Failure Pilot Survey (ESC-HF Pilot). Eur J Heart Fail 2010; 12: 1076-1084. 2010/09/02. DOI: 10.1093/eurjhf/hfq154.

16. Miro O, Hazlitt M, Escalada X, et al. Effects of the intensity of prehospital treatment on short-term outcomes in patients with acute heart failure: the SEMICA-2 study. Clin Res Cardiol 2018; 107: 347. DOI: 10.1007/s00392-017-1190-2 [doi].

17. Pivetta E, Goffi A, Lupia E, et al. Lung Ultrasound-Implemented Diagnosis of Acute Decompensated Heart Failure in the ED: A SIMEU Multicenter Study. Chest 2015; 148: 202. DOI: S0012- 
3692(15)50036-6 [pii].

18. Laribi S, Keijzers G, van Meer O, et al. Epidemiology of patients presenting with dyspnea to emergency departments in Europe and the Asia-Pacific region. Eur J Emerg Med 2019; 26: 345-349. DOI: 10.1097/MEJ.0000000000000571.

19. Gil V, Miro O, Schull MJ, et al. Emergency Heart Failure Mortality Risk Grade score performance for 7day mortality prediction in patients with heart failure attended at the emergency department: validation in a Spanish cohort. Eur J Emerg Med 2018; 25: 169-177. 2016/09/14. DOI: 10.1097/MEJ.0000000000000422.

20. Peterson PN, Rumsfeld JS, Liang L, et al. A validated risk score for in-hospital mortality in patients with heart failure from the American Heart Association get with the guidelines program. Circ Cardiovasc Qual Outcomes 2010; 3: 25-32. 2010/02/04. DOI: 10.1161/CIRCOUTCOMES.109.854877.

21. Siirila-Waris K, Lassus J, Melin J, et al. Characteristics, outcomes, and predictors of 1-year mortality in patients hospitalized for acute heart failure. Eur Heart J 2006; 27: 3011-3017. 2006/11/28. DOI: 10.1093/eurheartj/ehl407.

22. Harjola VP, Lassus J, Sionis A, et al. Clinical picture and risk prediction of short-term mortality in cardiogenic shock. Eur J Heart Fail 2015; 17: 501-509. 2015/03/31. DOl: 10.1002/ejhf.260.

23. Keijzers G, Kelly AM, Cullen L, et al. Heart failure in patients presenting with dyspnoea to the emergency department in the Asia Pacific region: an observational study. BMJ Open 2017; 7: e013812. 2017/03/02. DOI: 10.1136/bmjopen-2016-013812.

24. Dickstein K, Cohen-Solal A, Filippatos G, et al. ESC guidelines for the diagnosis and treatment of acute and chronic heart failure 2008: the Task Force for the diagnosis and treatment of acute and chronic heart failure 2008 of the European Society of Cardiology. Developed in collaboration with the Heart Failure Association of the ESC (HFA) and endorsed by the European Society of Intensive Care Medicine (ESICM). Eur J Heart Fail 2008; 10: 933-989. 2008 Sep 16. DOI:

0.1016/j.ejheart.2008.08.005.

25. Prekker ME, Feemster LC, Hough CL, et al. The epidemiology and outcome of prehospital respiratory distress. Acad Emerg Med 2014; 21: 543-550. 2014/05/21. DOI: 10.1111/acem. 12380.

26. Javaloyes P, Miro O, Gil V, et al. Clinical phenotypes of acute heart failure based on signs and symptoms of perfusion and congestion at emergency department presentation and their relationship with patient management and outcomes. Eur J Heart Fail 2019; 21: 1353-1365. 2019/05/28. DOI: 10.1002/ejhf.1502.

27. Lee DS, Schull MJ, Alter DA, et al. Early deaths in patients with heart failure discharged from the emergency department: a population-based analysis. Circ Heart Fail 2010; 3: 228-235. 2010/01/29. DOI: 10.1161/CIRCHEARTFAILURE.109.885285.

28. Kataja A, Tarvasmaki T, Lassus J, et al. Altered mental status predicts mortality in cardiogenic shock - results from the CardShock study. Eur Heart J Acute Cardiovasc Care 2018; 7: 38-44. 2017/04/14. DOI: $10.1177 / 2048872617702505$. 


\section{Tables}

Page 12/19 
Table 1. Patient characteristics

\begin{tabular}{|c|c|c|}
\hline All, $n=500$ & EMS, $n=309$ & Non-EMS, $n=191$ \\
\hline $\begin{array}{l}\text { missing } \\
(\mathrm{n})\end{array}$ & $\begin{array}{l}\text { missing } \\
\text { (n) }\end{array}$ & $\operatorname{missing}_{(\mathrm{n})}$ \\
\hline
\end{tabular}

\section{Demographics}

\begin{tabular}{|c|c|c|c|c|c|c|c|}
\hline Age, years & $\begin{array}{l}78(69- \\
84)\end{array}$ & & $\begin{array}{l}80(71- \\
85)\end{array}$ & & $\begin{array}{l}75(65- \\
81)\end{array}$ & & $<0.001$ \\
\hline $\begin{array}{l}\text { Duration of symptoms } \\
\text { (days) }\end{array}$ & $3(1-7)$ & & $3(1-7)$ & & $\begin{array}{l}3(2- \\
10)\end{array}$ & & 0.002 \\
\hline Gender (male) n (\%) & $\begin{array}{l}244 \\
(49.1)\end{array}$ & & $\begin{array}{l}134 \\
(43.6)\end{array}$ & & $\begin{array}{l}110 \\
(57.9)\end{array}$ & & 0.002 \\
\hline \multicolumn{8}{|l|}{ Comorbidities, n (\%) } \\
\hline Previous heart failure & $\begin{array}{l}290 \\
(60.9)\end{array}$ & & $\begin{array}{l}180 \\
(61.6)\end{array}$ & & $\begin{array}{l}110 \\
(59.8)\end{array}$ & & 0.685 \\
\hline Diabetes & $\begin{array}{l}188 \\
(38.2)\end{array}$ & & $\begin{array}{l}100 \\
(32.8)\end{array}$ & & $\begin{array}{l}88 \\
(47.1)\end{array}$ & & 0.002 \\
\hline Hypertension & $\begin{array}{l}348 \\
(71.0)\end{array}$ & & $\begin{array}{l}225 \\
(73.8)\end{array}$ & & $\begin{array}{l}123 \\
(66.5)\end{array}$ & & 0.085 \\
\hline Prior atrial fibrillation & $\begin{array}{l}175 \\
(35.7)\end{array}$ & & $\begin{array}{l}110 \\
(36.3)\end{array}$ & & $\begin{array}{l}65 \\
(34.8)\end{array}$ & & 0.729 \\
\hline COPD & $\begin{array}{l}128 \\
(27.6)\end{array}$ & & $\begin{array}{l}82 \\
(28.8)\end{array}$ & & $\begin{array}{l}46 \\
(25.8)\end{array}$ & & 0.493 \\
\hline Smoker & $\begin{array}{l}79 \\
(17.9)\end{array}$ & $\begin{array}{l}61 \\
(12.2)\end{array}$ & $\begin{array}{l}49 \\
(18.4)\end{array}$ & $\begin{array}{l}43 \\
(13.9)\end{array}$ & $\begin{array}{l}30 \\
(17.0)\end{array}$ & $15(7.9)$ & 0.712 \\
\hline Asthma & $32(6.8)$ & & $19(6.5)$ & & $\begin{array}{l}13 \\
(7.3)\end{array}$ & & 0.725 \\
\hline $\begin{array}{l}\text { Ischemic heart } \\
\text { disease }\end{array}$ & $\begin{array}{l}197 \\
(41.6)\end{array}$ & & $\begin{array}{l}120 \\
(41.1)\end{array}$ & & $\begin{array}{l}77 \\
(42.5)\end{array}$ & & 0.757 \\
\hline Dyslipidaemia & $\begin{array}{l}168 \\
(35.8)\end{array}$ & & $\begin{array}{l}93 \\
(32.5)\end{array}$ & & $\begin{array}{l}75 \\
(41.0)\end{array}$ & & 0.062 \\
\hline Renal impairment & $\begin{array}{l}119 \\
(25.2)\end{array}$ & & $\begin{array}{l}80 \\
(27.4)\end{array}$ & & $\begin{array}{l}39 \\
(21.7)\end{array}$ & & 0.164 \\
\hline Valvular disease & $\begin{array}{l}86 \\
(18.1)\end{array}$ & & $\begin{array}{l}57 \\
(19.5)\end{array}$ & & $\begin{array}{l}29 \\
(15.9)\end{array}$ & & 0.333 \\
\hline Anaemia & $\begin{array}{l}76 \\
(16.3)\end{array}$ & & $\begin{array}{l}47 \\
(16.4)\end{array}$ & & $\begin{array}{l}29 \\
(16.2)\end{array}$ & & 0.947 \\
\hline
\end{tabular}




\begin{tabular}{|lllll|} 
Active cancer & $30(6.5)$ & $17(6.0)$ & 13 & 0.572 \\
\hline Prior PE & $21(4.3)$ & $19(6.3)$ & $2(1.1)$ & 0.007 \\
\hline Obesity & 117 & 75 & 42 & 0.574 \\
& $(24.9)$ & $(25.8)$ & $(23.5)$ & 0.001 \\
\hline Dementia & 67 & 54 & 13 & \\
\hline
\end{tabular}

The values are given either as number (\%) or median (interquartile range)

$\mathrm{COPD}=$ chronic obstructive pulmonary embolism

$\mathrm{PE}=$ pulmonary embolism 
Table 2. Clinical characteristics on admission

All AHF, $n=500$

Vital signs

Missing

(n)

$\mathrm{SBP}<100 \mathrm{mmHg}, \quad 27(5.5)$

$\mathrm{n}(\%)$

$\mathrm{SBP}>140 \mathrm{mmHg}, \quad 243(49.3)$

$\mathrm{n}(\%)$

$\mathrm{SBP}(\mathrm{mmHg})$

$\operatorname{DBP}(\mathrm{mmHg})$

$80(66-91)$

Heart rate $>10$
bpm, $\mathrm{n}(\%)$

Hear rate $>120$

bpm, n (\%)

Respiratory rate, 22 (18-28)

(per min)

Respiratory rate $\quad 55(13.3)$

$>30 /$ min, $n(\%)$

$\mathrm{SpO}_{2}(\%)$ with

supplementary $\mathrm{O}_{2}$

$\mathrm{SpO}_{2}<90 \%$ with $\quad 118(24.5)$

supplementary

$\mathrm{O}_{2}, \mathrm{n}(\%)$

Temperature $\left({ }^{\circ} \mathrm{C}\right) \quad 36.5(36.0-$

$$
36.9)
$$

EMS- patients, $n=309$

Missing(n)

Non-EMS-

patients, $n=191$

p-
value

Missing

(n)
140 (120-

159)

$80(66-91)$

88 (75-

110)

$160(32.5)$

52 (10.6)

$18(5.9)$

146

(47.9)

140

(120-

156)

80 (66-

92)

90 (75-

110)

111

(36.4)

38

(12.5)

24 (19-

30)

$94(90-97)$

89
$(17.8)$

43

(17.1)

94 (90-

97)

71

(23.7)
(4.8)

97

(51.6)

143

(122-

162)

80

(67-

90)

85

(75-

104)

49

(26.2)

14

(7.5)

0.115

0.801

0.421

0.285

0.597

0.421

0.285

(2)

21

(18-

26)

$\begin{array}{lll}12 & 30 & 0.005 \\ (7.5) & (15.7) & \end{array}$

94

(89-

0.569

96)

47

(25.8)

0.607

36.5

(36.0-

36.5

(36.0-

0.262

\section{Clinical signs, $\mathrm{n}(\%)$}

Rales on

auscultation

Wheezing on
346 (71.8)

228

(76.8)

87 (19.7)

58

62

118

(63.8)

0.002

Page 15/19 


\begin{tabular}{|c|c|c|c|c|c|c|c|}
\hline \multicolumn{2}{|l|}{ auscultation } & \multirow[t]{2}{*}{ (11.6) } & \multicolumn{2}{|l|}{$(23.1)$} & \multicolumn{3}{|l|}{$(14.4)$} \\
\hline $\begin{array}{l}\text { Peripheral } \\
\text { oedema }\end{array}$ & $273(56.2)$ & & $\begin{array}{l}173 \\
(58.1)\end{array}$ & & $\begin{array}{l}100 \\
(53.2)\end{array}$ & & 0.293 \\
\hline $\begin{array}{l}\text { Jugular vein } \\
\text { distension }\end{array}$ & $110(25.1)$ & $\begin{array}{l}62 \\
(12.4)\end{array}$ & $\begin{array}{l}72 \\
(27.4)\end{array}$ & $46(14.9)$ & $\begin{array}{l}38 \\
(21.7)\end{array}$ & $16(8.4)$ & 0.181 \\
\hline Confusion & $47(9.6)$ & & $\begin{array}{l}43 \\
(14.2)\end{array}$ & & $\begin{array}{l}4 \\
(2.1)\end{array}$ & & $<0.001$ \\
\hline \multicolumn{8}{|c|}{ Laboratory parameters } \\
\hline $\begin{array}{l}\text { NT-proBNP } \\
(\mathrm{pg} / \mathrm{mL})\end{array}$ & $\begin{array}{l}3661(1328- \\
10377)\end{array}$ & $\begin{array}{l}381 \\
(76.2)\end{array}$ & $\begin{array}{l}5144 \\
(1846- \\
11205)\end{array}$ & $223(72.2)$ & $\begin{array}{l}2103 \\
(688- \\
5167)\end{array}$ & $\begin{array}{l}155 \\
(81.2)\end{array}$ & 0.001 \\
\hline $\begin{array}{l}\text { Creatinine } \\
(\mu \mathrm{mol} / \mathrm{L})\end{array}$ & $\begin{array}{l}101(78- \\
136)\end{array}$ & & $\begin{array}{l}107 \text { (77- } \\
137)\end{array}$ & & $\begin{array}{l}94 \\
(80- \\
131)\end{array}$ & & 0.751 \\
\hline Sodium (mmol/L) & $\begin{array}{l}138(136- \\
141)\end{array}$ & & $\begin{array}{l}138 \\
(135- \\
141)\end{array}$ & & $\begin{array}{l}138 \\
(136- \\
141)\end{array}$ & & 0.476 \\
\hline $\begin{array}{l}\text { Potassium } \\
\text { (mmol/L) }\end{array}$ & $\begin{array}{l}4.3(4.0- \\
4.8)\end{array}$ & & $\begin{array}{l}4.3(4.0- \\
4.8)\end{array}$ & & $\begin{array}{l}4.3 \\
(3.9- \\
4.7)\end{array}$ & & 0.243 \\
\hline $\mathrm{CRP}(\mathrm{mg} / \mathrm{dL})$ & $10(4-30)$ & & $\begin{array}{l}13(5- \\
41)\end{array}$ & & $\begin{array}{l}8(3- \\
20)\end{array}$ & & 0.003 \\
\hline $\mathrm{pH}$ & $\begin{array}{l}7.40(7.34- \\
7.45)\end{array}$ & & $\begin{array}{l}7.38 \\
(7.32- \\
7.44)\end{array}$ & & $\begin{array}{l}7.43 \\
(7.37- \\
7.46)\end{array}$ & & 0.001 \\
\hline $\mathrm{PaCO}_{2}(\mathrm{mmHg})$ & $\begin{array}{l}38.0(31.6- \\
45.5)\end{array}$ & & $\begin{array}{l}39.2 \\
(31.5- \\
46.0)\end{array}$ & & $\begin{array}{l}36.0 \\
(32.0- \\
43.1)\end{array}$ & & 0.296 \\
\hline $\begin{array}{l}\text { White cell count } \\
\left(10^{9} / \mathrm{L}\right)\end{array}$ & $\begin{array}{l}9.0(7.0- \\
11.5)\end{array}$ & & $\begin{array}{l}9.0(7.0- \\
13)\end{array}$ & & $\begin{array}{l}8.8 \\
(6.8- \\
10.2)\end{array}$ & & 0.070 \\
\hline $\begin{array}{l}\text { Haemoglobin } \\
(\mathrm{g} / \mathrm{dL})\end{array}$ & $\begin{array}{l}12.3(10.7- \\
13.9)\end{array}$ & & $\begin{array}{l}12.2 \\
(10.6- \\
13.7)\end{array}$ & & $\begin{array}{l}12.3 \\
(10.7- \\
14.0)\end{array}$ & & 0.626 \\
\hline $\begin{array}{l}\text { Haemoglobin } \\
<100 \mathrm{~g} / \mathrm{L} \text {, } \mathrm{n}(\%)\end{array}$ & $58(12.9)$ & $\begin{array}{l}51 \\
(10.2)\end{array}$ & $\begin{array}{l}38 \\
(13.8)\end{array}$ & $33(10.7)$ & $\begin{array}{l}20 \\
(11.6)\end{array}$ & $18(9.4)$ & 0.497 \\
\hline
\end{tabular}

The values are given either as number (\%) or median (interquartile range)

$\mathrm{SBP}=$ systolic blood pressure 
DBP=diastolic blood pressure

$\mathrm{SpO}_{2}=$ peripheral oxygen saturation

\section{Figures}

\section{Diagnostic tests in ED}

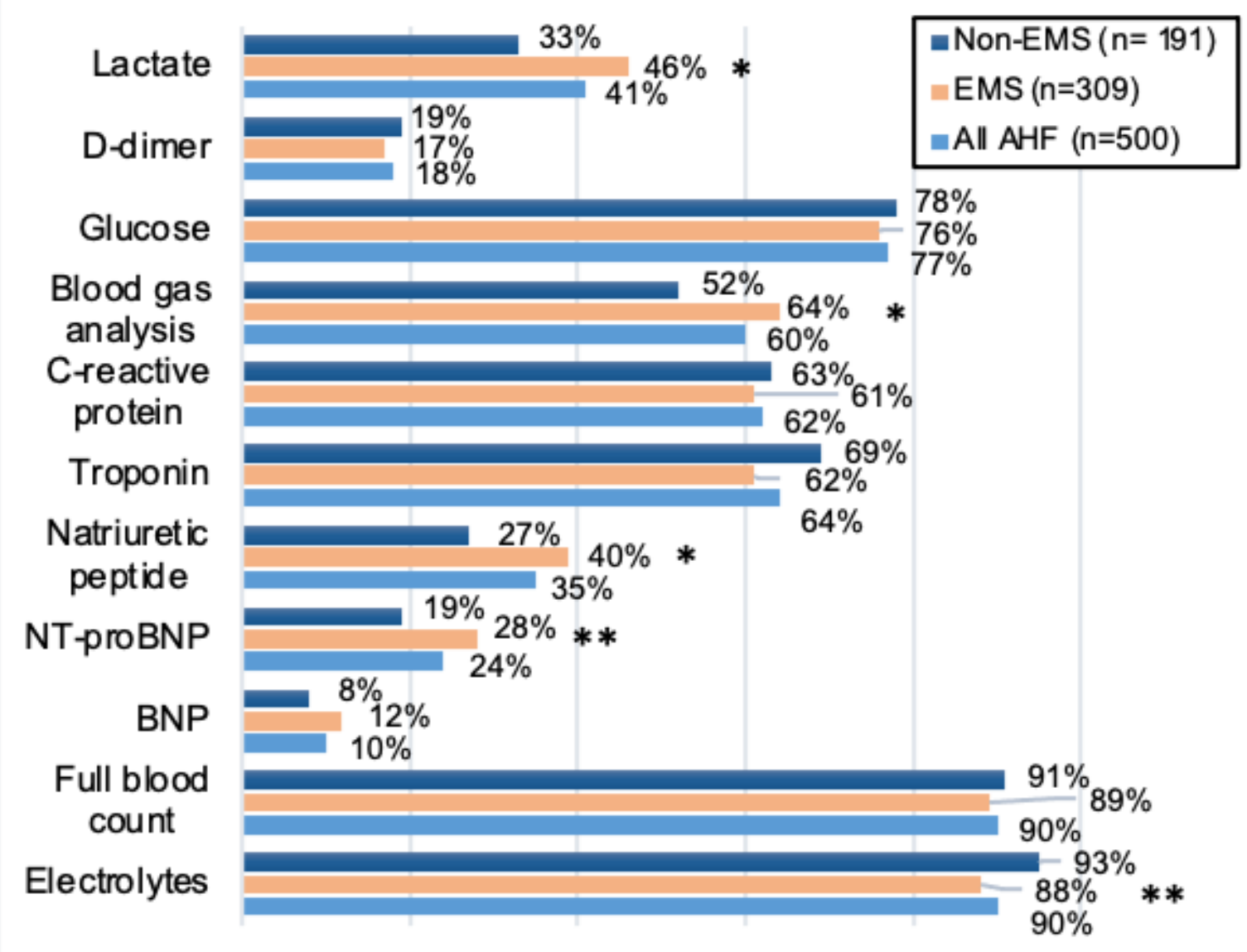

Figure 1

The frequency of diagnostic tests on admission to emergency department * $p<0.01 * \star p<0.05 P$-values are for comparison between EMS and non-EMS patients 


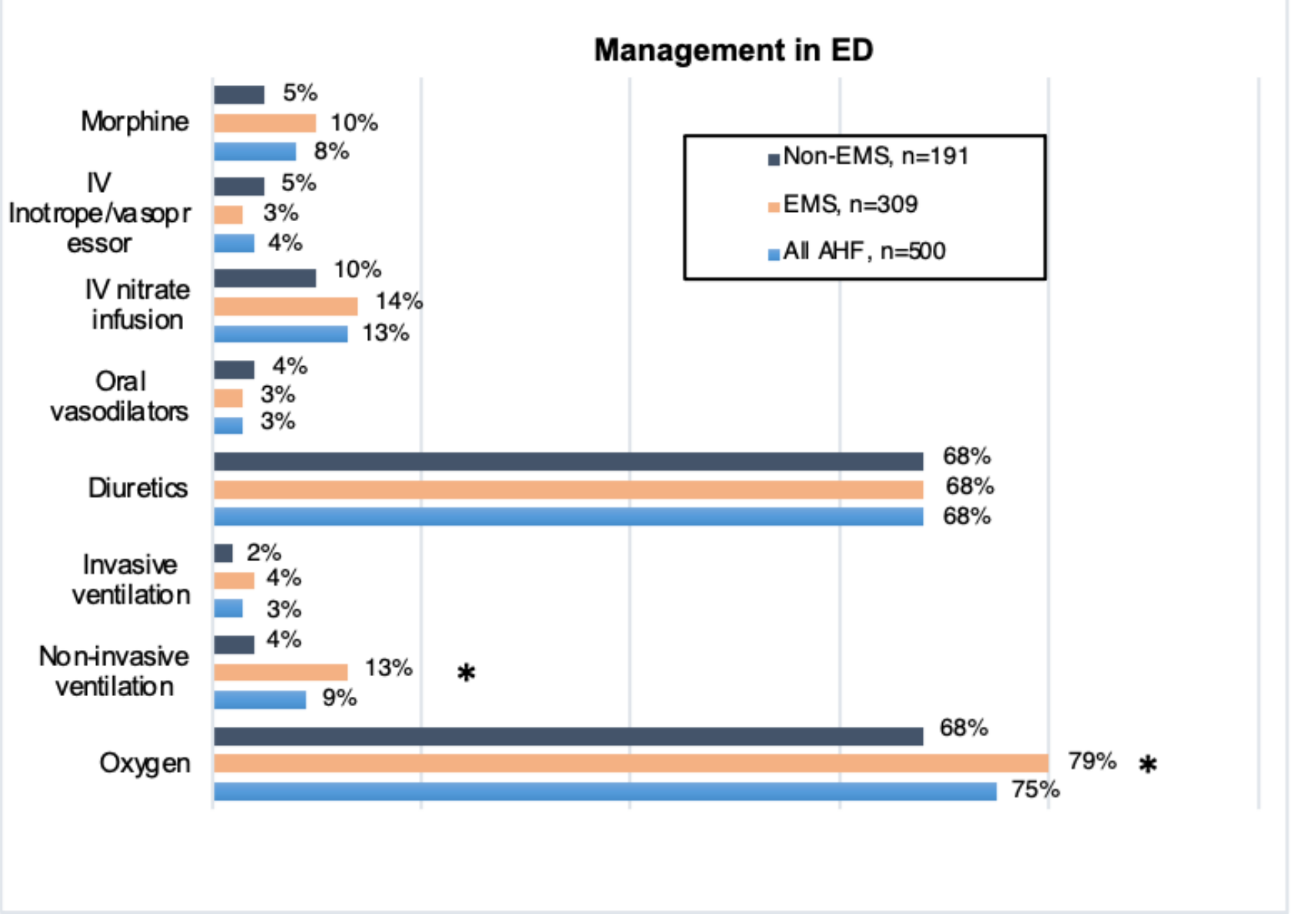

Figure 2

Acute heart failure management on admission to emergency department * $p<0.01$ P-values are for comparison between EMS and non-EMS patients 


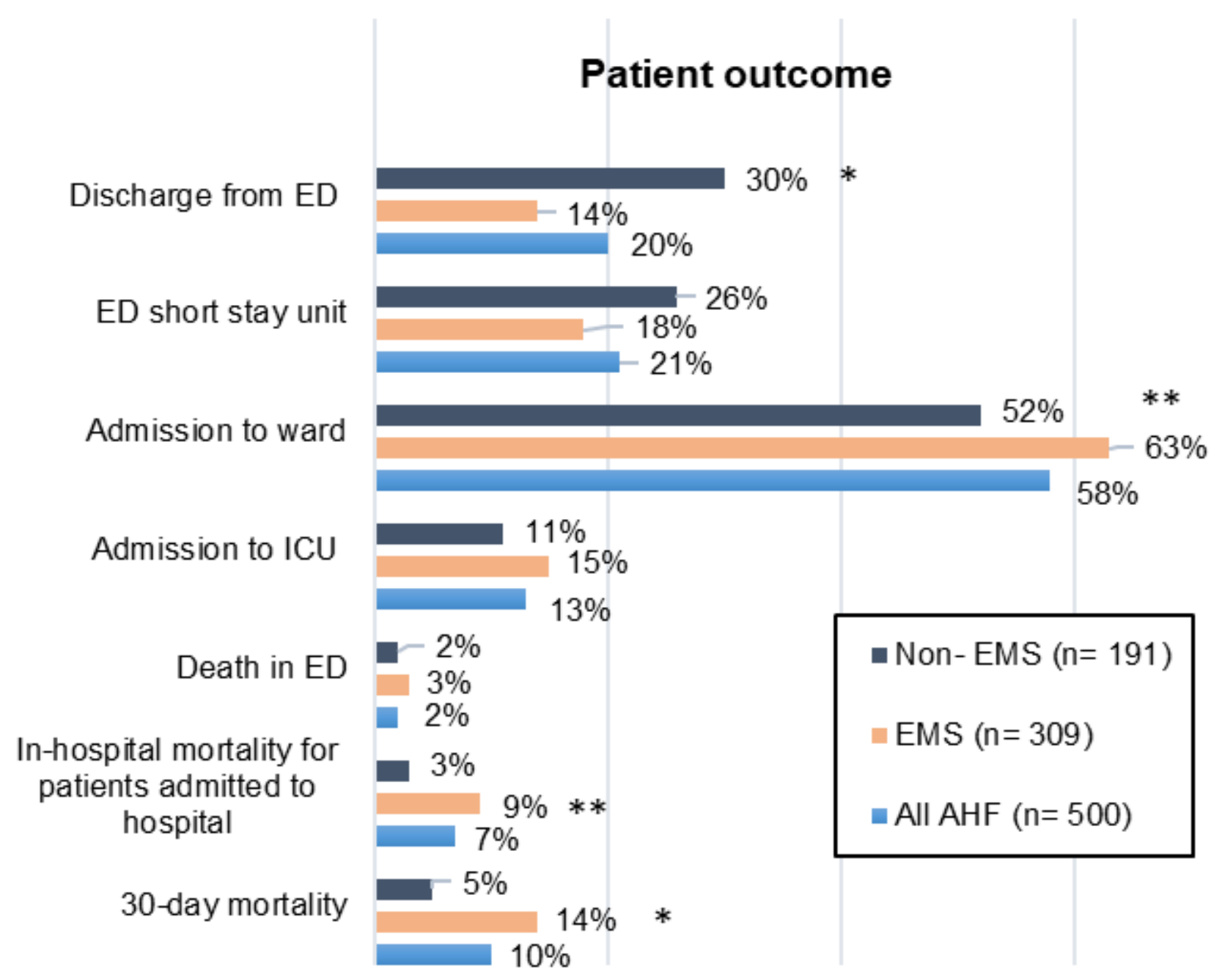

Figure 3

Patient outcomes ICU = intensive care unit, ED= emergency department * $p<0.001$ ** $p<0.05$ P-values are for comparison between EMS and non-EMS patients

\section{Supplementary Files}

This is a list of supplementary files associated with this preprint. Click to download.

- EURODEMstudygroupmembers.docx 